\section{Assessing the effect of organisational commitment on turnover intentions amongst Islamic bank employees}

\author{
Carole Serhan, Nehmeh Nehmeh and Ibrahim Sioufi \\ University of Balamand, Tripoli, Lebanon
}

Turnover intentions for IB employees

Received 19 January 2021 Revised 10 February 2021 8 July 2021

18 November 2021 21 November 2021 17 December 2021

Abstract

Purpose - The research aims to test the links amongst Meyer and Allen's three levels of organisational commitment and the commitment's effect on reducing turnover intentions for Islamic bank (IB) employees during the lockdown caused by coronavirus disease (COVID-19).

Design/methodology/approach - The research follows a variable-centred approach. Primary data are collected through a survey of 324 respondents comprising IB employees from three Arab countries, notably the United Arab Emirates (UAE), Lebanon and Oman. Exploratory factor analysis (EFA) and Cronbach's alpha test are conducted to test the construct validity, reliability and internal consistency of collected data. Descriptive statistics are used to interpret the data. Zero-order correlations, multiple regression analysis and Fisher's $Z$-test are applied to assess the interrelations of the various groups of variables and the determinants of turnover intentions.

Findings - Results show that there is a high level of significant intercorrelation amongst affective, normative and continuance commitments as well as amongst organisational commitment, individual differences and turnover intentions for IB employees from the three studied Arab countries. The results confirmed that turnover intentions are minimised in the presence of all three organisational commitment subscales and that individual differences amongst IB employees and organisational efficiency moderate the relationship between organisational commitment and turnover intentions.

Originality/value - There is no empirical work that has been done on the determinants of turnover intentions amongst IB employees during the lockdown. This is valuable to organisational behaviour scholars and practitioners who are interested in the role that organisational commitment plays in IB's employment behaviour.

Keywords Individual differences, Islamic bank, Organisational commitment, Organisational efficiency,

Turnover intentions

Paper type Research paper

\section{Introduction}

As acknowledged since long time ago, employees have various commitment behaviours towards their careers (Delistavrou et al., 2019). As per the three-component model (Meyer and Allen, 1991, Allen and Meyer, 1993; Meyer et al., 1993), commitment is categorised into three different attitudes: "affective commitment", i.e. an intention to stay within the same job; "normative commitment", i.e. an obligation to stay in the job and "continuance commitment", i.e. a need to stay. It has been extensively proven that those attitudes are significant, with affective commitment being strongly positively correlated to organisational outcomes (e.g. job performance and retention), whilst normative and continuance commitments show weaker links varying from positive to negative (Serhan and Tsangari, 2019).

(C) Carole Serhan, Nehmeh Nehmeh and Ibrahim Sioufi. Published in ISRA International Journal of Islamic Finance. Published by Emerald Publishing Limited. This article is published under the Creative Commons Attribution (CC BY 4.0) licence. Anyone may reproduce, distribute, translate and create derivative works of this article (for both commercial and non-commercial purposes), subject to full attribution to the original publication and authors. The full terms of this licence maybe seen at http:// creativecommons.org/licences/by/4.0/legalcode.
Accepted 20 December 2021

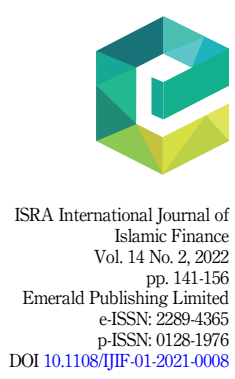


IJIF

14,2

142

So far many scholars investigating the effects of employee commitment have tested these links related to individual attitudes using cluster analysis and latent profile analysis (e.g. Long and Thean, 2011; Meyer et al., 2018). More recently, the variable-centred approach has been used, as it is more appropriate to examine the potentially more multifaceted effect of affective, normative and continuance commitment links (Meyer and Allen, 1997; Maertz and Boyar, 2012; Jehanzeb et al., 2013; Redditt et al., 2019). The use of this approach enables scholars to categorise clusters of persons with various commitment intensities and to assess the links amongst all related variables (Maertz and Boyar, 2012; Rawashdeh and Tamimi, 2019).

This research extends variable-centred commitment research in various ways. First, it examines the organisational commitment and its effect on turnover intention amongst employees of IBs during the 2020 lockdown period in various Arab countries. This lockdown arguably created enormous confusion that was translated by the switch of many employees across IBs during the lockdown, perhaps because the lockdown was generally viewed as a direct cause of the economic crisis (Algabry et al., 2020). Indeed, the lockdown that hit major Arab countries in 2020 affected deeply the countries and the banks under investigation (Ali, 2020). Second, it incorporates new outcome variables to assess the construct validity of the data collected. Indeed, outcome variables (e.g. turnover intentions) were extended to allow a better examination of the potential links amongst the three different commitment attitudes and potential work outcomes. Moderator variables (e.g. individual differences and organisational efficiency) were also integrated to examine the different groups of organisational and individuals' effects on the abovementioned links (groups being classified by age, gender, social rank, etc.).

In brief, the lockdown that struck the Arab countries offered the chance for a natural quasi-experiment that could add to knowledge by being one of the first few investigations of the effects of commitment on turnover intentions during the lockdown (Shierholz et al., 2012; Meyer et al., 2018; TahiriJouti, 2018; Ali, 2020; Benaicha, 2020). The study also serves as the first investigation to use a variable-centred approach in a non-Western context and more particularly amongst IBs in Arab world countries.

\section{Literature review}

\section{Meyer and Allen's model of organisational commitment}

Out of more than 15 articles, Meyer and Allen have added the most to the organisational research on commitment. For this reason, their commitment model is selected as a consequence of the methodological appraisal that has to date been more comprehensive than others (Meyer and Allen, 1991; Allen and Meyer, 1996; Rawashdeh and Tamimi, 2019).

Allen and Meyer (1990) built up their model by identifying universal concepts. In accordance with other models, they retained the idea that commitment links individuals to their companies. The biggest contrast remains in the manner the commitment is expected to be revealed. Three distinctive themes were expressed as follows: "affective attachment", "normative commitment" and "continuance commitment" (Allen and Meyer, 1984).

"Affective commitment" is an attitude towards an organisation; it relates a person's personality to the organisation (Sheldon, 1971). Hall (1970) and Moussa (2013) define the affective aspect as an increasingly concordant cycle of the concerns of the individual and the organisation.

"Continuance commitment" is the desire to continue working in an organisation because of the awareness of the overheads related to quitting it (Thrassou et al., 2020).

"Normative commitment" is the feeling of obligation that workers feel towards a business regardless of the degree of the company's reputation enhancement or fulfilment over time (Dey, 2012; Mallat et al., 2020).

Allen and Meyer (1996) call on scholars to investigate how multi-dimensional conceptualisations formed in the USA would extend to other societies in terms of 
dimensionality of organisational engagement through societies. In their study, they analyse outcomes from various experiments and conclude the adequacy of the system integrity to support the usage of scales. The fact that the commitment model has only been tested in Western countries reveals the necessity for further methodical research to verify the applicability of this model elsewhere (Kraska et al., 2017). More particularly, no testing of it has been done in Eastern countries or in IBs. Thus, Meyer and Allen's commitment model is used as the foundation for this research.

\section{Organisational commitment and employee turnover}

Porter (1974) defines organisational commitment as one's actual aptitude to participate in a particular organisation. The concept of organisational commitment encompasses three dimensions as follows: employee recognition of and confidence in the values of the company; commitment towards the company so as to make substantial efforts and readiness to continue in the same company (Mowday et al., 1979). Firestone and Pennell (1993) describe the commitment concept as an inward association or identification of an individual with someone outside of himself/herself. Cohen (2003) says that commitment is an action binding a person to one or more goals. Another definition is given by Al-Jabari and Ghazzawi (2019) who define organisational commitment as being a voluntary act that is far away from an employee's obligation, which extensively improves the efficiency of the whole company. As for this research, the definition of organisational commitment relates mainly to Meyer and Allen's (1991) commitment concept. Thus, organisational commitment is the psychological attachment that persons have towards their companies and is characterised by influencing the decision to stay in or leave the company.

Turnover intentions refer to employees' intentions to quit their jobs (Kim and Jogaratnam, 2010), whilst organisational commitment is the degree of affection that an employee shows towards the company he/she is employed in (Vrontis et al., 2015; Serhan et al., 2016). Knowing that turnover intentions have negative impact on the efficiency of a company, managers look for various ways to increase the stay of their workers (Moussa, 2013). High turnover rates significantly increase the company's financial costs (Redditt et al., 2019).

Employee turnover rates have increased lately especially because of the high-competition levels amongst companies as well as the increased need for experienced and knowledgeable employees (Kim and Jogaratnam, 2010; Serhan and Tsangari, 2019; Benaicha, 2020). This explains the significance of the topic in organisational behaviour studies (Pitts et al., 2011). Employees quit their jobs for many reasons (Serhan et al., 2016). Many scholars (e.g. Maertz and Boyar, 2012; Rawashdeh and Tamimi, 2019) asserted that organisational commitment significantly affects turnover intentions in various fields. Thrassou et al. (2020) discovered that organisational commitment is negatively linked to turnover intention. On the contrary, Vrontis et al. (2015) demonstrated that organisational commitment and turnover intention are positively linked. Similarly, Shang et al. (2019) stated that even though organisational commitment and turnover intentions are generally positively linked, diverse kinds of organisational commitment bring about dissimilar outcomes.

Turnover intention was tested through different scales that were created for this purpose (Jehanzeb et al., 2013). Babajide (2010) created and tested one such scale, and Pitts et al. (2011) developed a similar one. Amongst all these instruments, the Michigan organisational assessment scale is the most frequently used (Kumari, 2017). However, none of these scales could serve as a basis for this study, as none of them takes into the consideration the special context of IBs.

The extant literature related to the impact that organisational commitment has on turnover intentions has mainly focussed on its manifestation in healthcare. There is thus a need for more studies of other industrial and commercial sectors, which would likely enrich the knowledge of organisational behaviour and decrease the costs associated with high turnover.

\section{Turnover intentions for IB employees}


IJIF

14,2

144

\section{Islamic banking context}

Knowing that the vast majority of organisational commitment studies have been carried out in Western countries and that there is a shortage of studies in other cultures, this study tackles the cross-cultural applicability of Meyer and Allen's model of organisational commitment, which was raised by various scholars (e.g. Ali, 2020). The study deals with the evaluation of the model in the context of IBs in the Arab world.

IBs are based on two main purposes: removing income inequality and bringing social justice. These purposes cannot be attained unless all financial institutions contribute in a positive manner towards them (Rafikov and Akhmetova, 2020). IBs have witnessed a stable and constant expansion for the last decade following the global financial crisis of 2007-2008. Their ability to remain solvent and stay profitable throughout and after this crisis has called attention to Islamic banking as a sustainable financial system (Islam and Ahmad, 2020).

Various scholars (e.g. Algabry et al., 2020; Ali, 2020; Zivković et al., 2021) agree that the current pandemic and its economic effects are of enormous magnitude. There are still no available solutions to the economic and financial damages of the current crisis.

Several Islamic scholars (e.g. Algabry et al., 2020; Islam and Ahmad, 2020) argue that IBs are not only able to fight the economic effects of the pandemic and lockdown, but also have the capacity to come out as a substitute for the current financial system. Indeed, owing to their intrinsic power vis-à-vis the current financial system, IBs have a lot to offer. In this context, it is asked whether IBs are good enough to retain their employees in the economic crisis created by the current pandemic and lockdown (Rafikov and Akhmetova, 2020).

A systematic examination of existing literature did not show theoretical or practical research evidence about employees' organisational commitment and intention to quit existing employment in the context of an Eastern country or in IBs. Thus, this research seeks to partially fill the gaps in research and practice. This represents an incentive to conduct further studies to provide the foundation for more empirical exploration.

Various Arab industries and commercial centres are private proprietorships, and employees' control over their job conditions is very low (Akram and Rahman, 2018). Market competition is very complex and not always a constructive process. Despite the similar starting positions, employees in different IBs are being paid very different wages (Hussain et al., 2020). In this new context, the relation that links employees to their banks has become more important from the practical as well as theoretical point of view. Employees working at profitable banks have significantly better living standards and higher feelings of job security (Guzeller and Celiker, 2020). In light of the above, one of the purposes of this research is to check whether organisational efficiency has a moderating effect on the correlation that links organisational commitment to turnover intentions in the Eastern context.

\section{Emerging model and hypotheses}

The present study collects data as part of an organisational behaviour study completed in various IBs in the UAE, Lebanon and Oman. Throughout March 2020, during the period of data collection, lockdowns were being imposed in these countries. Thus, one primary research question is whether the work environment affected by the lockdown could have indirect consequences on the link between organisational commitment and turnover intention and related correlates and outcomes.

For the main objective of the current research, the three types of Meyer and Allen's organisational commitments are used to test their simultaneous effect on turnover intentions. Thus, it is suggested to insert a newly added outcome related to turnover intentions and incorporate moderating variables, being mainly individual differences and organisational efficiency.

The main components of the proposed model thus comprise the following: 
(1) Organisational commitment, which includes the affective, normative and continuance commitments;

(2) Moderating variables including organisational efficiency and three individual differences: age, gender and social rank and

(3) Turnover intentions.

At this point, an enquiry is raised: To what degree do these factors truly contribute to turnover intentions in IBs during the lockdown?

With reference to various organisational behaviour theories, this relational model will assess the simultaneous effect of the abovementioned sets of variables, i.e. organisational commitment and turnover intentions taking into consideration the moderation effect of organisational efficiency and individual differences.

These relationships extensively described in the study were translated into hypotheses aiming to assess the significance of the effect of various types of organisational commitment on turnover intentions in IBs as follows:

H1. Turnover intentions are affected by the three components of organisational commitment amongst IB employees in times of lockdown.

SH1.1. "Affective commitment" is significantly negatively linked to "turnover intentions";

SH1.2. "Continuance commitment" is significantly negatively linked to "turnover intentions";

SH1.3. "Normative commitment" is significantly negatively linked to "turnover intentions" and

SH1.4. In the presence of the three components of organisational commitment, turnover intentions are minimised.

Over and above commitment, the study includes measurements of some variables that have been recognised as moderators of commitment, which enable testing a hypothesis related to links between these variables and their effect on the influence of organisational commitment on turnover intentions and evaluating their moderating effects. The effects of these variables have been clearly verified in preceding research but not in variable-centred research (Morrow, 1983; Meyer et al., 2002). Thus, considerable evidence supports the prediction that individual differences as well as organisational efficiency have a moderator effect. Though it is expected that the direction of the relationships will remain the same, the strength of the relationships may vary. The second hypothesis is thus stated as follows:

H2. Individual differences and organisational efficiency are moderators affecting the link between organisational commitment and turnover intentions amongst IB employees during lockdown.

\section{Method}

Participants and procedures

A total of 324 participants belonging to various IBs in the UAE, Lebanon and Oman accepted to complete the questionnaire. Data collection took place from March to May 2020. The human resources department of each bank helped to distribute and collect the questionnaire in a sealed envelope and attached an informed consent detailing the aim of the research and guarantying employees that their answers will stay private. Contribution was not forced and was without remuneration. 
IJIF

14,2

146

The participants' mean age is 30.12 years [Standard Deviation (SD) 4.73] with the span ranging from 18 to 64 years old. The majority of these participants were females (51.5\%), in their thirties $(81 \%)$ and single $(77.5 \%)$. In total, $73.1 \%$ of the participants held a bachelor degree. Concerning their job position, a considerable number, $62.9 \%$ of participants, reported an administrative position such as clerk, whilst $12.9 \%$ hold a position of manager or supervisor. With regard to salaries, $46.9 \%$ of participants reported a salary between US $\$ 1,500$ and US $\$ 3,000.13 \%$ of the participants belonged to the upper social class. Cross tabulation of the participants' years of job experience and diversification of jobs shows that the sample is well qualified. This fact is attributed to the requirements set to be included in the sample. Data on social class were determined based on the three key measures that are most commonly used to determine social class in most business studies: education, income and occupation (Hofstede, 2001). Data on organisational efficiency were collected from the bank itself. It was estimated by objective profit data based on annual financial reports.

\section{Measures}

To measure the independent, dependent and moderator variables, the "Meyer and Allen's Commitment Scale" has been adopted, questions related to turnover intentions were added and statements aiming to assess the moderation effect of individual differences and organisational efficiency were integrated. The scale consists of 36 items classified into four subscales, the first being affective commitment; the second, normative commitment; the third, continuance commitment and the fourth, turnover intentions. These 36 items were a mixture of the 24 items of the basic instrument of Meyer et al. (1993) with 12 new items created for the purposes of the research to examine how much organisational commitment is properly related to turnover intentions in IBs and during lockdown. For testing organisational commitment, eight items each were combined to assess affective commitment (e.g. "This organisation has a great deal of personal meaning for me"), normative commitment (e.g. "I would feel guilty if I left this organisation right now") and continuance commitment (e.g. "If I decided to leave this organisation, too much of my life would be disrupted"). All measures related to organisational commitment used a five-point Likert-type response scale ranging from strongly disagree (1) to strongly agree (5). For testing turnover intentions, 12 items were used to measure turnover intentions (e.g. "How often do you think about quitting your job during the lockdown? Have you ever looked for a different job other than an IB?"). Responses to all items were made on five-point Likert-type scales ranging from never (1) to constantly (5), from very unlikely (1) to very likely (5) and from "never (1)" to "more than once a week" (5), respectively. Besides, some sociodemographic data named hereafter individual differences ( age, gender, marital status, social class, education, salary etc.) were collected for descriptive reasons and considered as independent variables in testing their moderating effect (see results section).

\section{Data analysis}

The validity and reliability of the new instrument were assessed. For demographic data and scale items, descriptive statistics were determined since they are the foundation of almost every quantitative data analysis (George and Mallery, 2010). Construct validity was checked by EFA to reveal the basic constitution of a considerable set of variables and to discover the underlying links amongst the studied variables. The process applied was used in similar studies of measuring construct validity (e.g. Bergjan and Hertel, 2013; Papastavrou et al., 2016). Internal consistency and reliability of the scales and subscales were tested with widely used reliability measures in related studies of psychometric properties, including "Cronbach's alpha", "item analysis", "Cronbach's alpha if item deleted" and "item-to-total correlations" (e.g. Cronbach, 1971; Tsangari, 2017). Finally, content validity was examined by a group of experts (academics in related areas) who were asked to check the content of each newly added question. 
The research hypotheses of interest were tested. This was performed through four separate groups of analyses, which are detailed as follows:

(1) Descriptive statistics for each subscale, aiming to summarise the data collected in a meaningful way so that patterns may emerge, including mean, standard deviation, skewness and kurtosis as well as Shapiro Wilk $p$-values to test for normality.

(2) Simple analysis (by zero-order correlation) of the links amongst the various subscales of the instrument. A Pearson correlation is considered statistically significant if the $p$-value $<\alpha$, the level of significance.

(3) Analysis (by simple and multiple regression) to determine if turnover intentions are minimised in the presence of the three components of organisational commitment. This is performed through examining a set of regressions predicting the turnover intentions subscales from all possible combinations of the three organisational commitment subscales to check if the amount of outcome subscale variance explained increases when additional commitment is further added to the regression equations. A variable is considered significant when $p$-value $<$ the level of significance, $\alpha, 5 \%$ (Tsangari, 2017).

(4) Analysis (by zero-order correlation and Fisher's Z-test) of the degree to which organisational efficiency and individual differences moderate the relationships between organisational commitment subscales and turnover intentions. More specifically, groups were created for organisational efficiency and individual differences subscales. Comparisons were made between the correlations in the groups of these subscales at the following potential sites: affective commitment with turnover intentions, normative commitment with turnover intentions and continuance commitment with turnover intentions. Fisher's $Z$ was then used to test the significance of the differences between corresponding correlations in the groups of individual differences and organisational commitment (Mosteller and Bush, 1954).

\section{Results}

Reliability analysis and factor loadings of commitment and turnover measures

The individual scale items. Descriptive statistics ("means", "standard deviations" and "skewness and kurtosis") for individual items are determined to examine if there is any inconsistency between the answers and to test for a considerable deviation from what is normal. The values of "skewness and kurtosis" are acceptable if answers are between -1.5 and +1.5 and excellent if answers are between -1 and +1 (George and Mallery, 2010). The item with the highest mean value relates to the continuance commitment subscale (Item 2.3 in Subscale 2 - "Too much in my life would be disrupted if I decided to leave my organisation now") with a mean of 6.1095 and a standard deviation of 1.22081. This latter shows an acceptable value of skewness and kurtosis. Even though in many items there is a minor tendency for a positive attitude ("mostly agree" and "strongly agree"), the value of "kurtosis and skewness" for items are all in the acceptable range. As a result, no changes were deemed essential and all items of all subscales were included in the analysis.

\section{Construct validity, internal consistency and reliability-item analysis}

EFA with Promax rotation is run on SPSS version 21.0 "SPSS, Inc., Chicago, IL, USA" to help determine the construct validity of the items. The process followed is the same as the one used in similar research (e.g. Vizcaya-Moreno et al., 2015). The appropriateness of the data for factor analysis is checked for each of the subscales with regards to Kaiser-Mayer-Olkin (KMO) measure and Bartlett's test of sphericity. For choosing subscales, eigenvalues should

\section{Turnover intentions for IB employees}


IJIF

14,2

148

be higher than one (Vizcaya-Moreno et al., 2015). Results show that the KMO measure has a value of $0.855>0.5$, showing a high adequacy of the sample. Bartlett's test of sphericity is significant $(p<0.001)$. Results of EFA with Promax rotation confirm the extraction of four subscales, which explains a total of $79.22 \%$ of the variance. The subscale with the highest eigenvalue was "affective commitment" with an eigenvalue of 3.122. All the subscales have satisfactory loadings that are higher than 0.5. All items of the new scale structure load in a significant way onto their corresponding subscales (loadings range from 0.520 to 0.906). No missing data existed in any item.

"Cronbach's alpha”, "item analysis", "Cronbach's alpha if item deleted" and "item-to-total correlations" are used to test the internal consistency and reliability of the scale and subscales similarly to what is widely used in related studies of psychometric properties. The reliability of the scale (Cronbach's alpha 0.832 higher than 0.65 ) has proved to be highly satisfactory. "Cronbach's alpha if item deleted" shows that all items are deemed reliable and are consequently kept in the corresponding scale.

The items are grouped on each corresponding factor according to the strength of their loadings. Thus, the instrument used offers the opportunity to measure all the elements of organisational commitment affecting employees' turnover intentions in a consistent way keeping in mind the characteristics of the various possible settings within which this tool could be evaluated.

\section{Organisational commitment and turnover intentions}

Throughout this section, the link amongst the various measures of the newly modified model is examined. Particularly, the relationships between (1) "affective commitment" and "normative commitment", (2) "affective commitment" and "continuance commitment", (3) "normative commitment" and "continuance commitment" and (4) "affective, normative and continuance commitments" and "turnover intentions" are evaluated using zero-order correlations. Then, multiple regression analysis is applied to examine the linkage between each subscale of organisational commitment and turnover intentions so as to determine whether in the presence of the three types of organisational commitments, turnover intentions are minimised.

\section{Zero-order correlations amongst measures}

As expected, Table 1 illustrates that the zero-order correlation amongst the subscales are all significant $(\phi<0.01)$ and are as follows: "affective commitment" is highly positively correlated to "normative commitment" (0.768) and to "continuance commitment" (0.504) and "normative commitment" is highly positively correlated to "continuance commitment" (0.492).

Concerning the relations between the subscales of organisational commitment and turnover commitment, results show that "affective commitment" has a high negative correlation with "turnover intentions" (-0.472), "continuance commitment" has a high negative correlation with "turnover intentions" $(-0.677)$ and "normative commitment" has a high negative correlation with "turnover intentions" $(-0.615)$.

In brief, the subscales are related to each other as proposed by the relational framework on which the scale is based. In particular, turnover intentions relate negatively and significantly to the other subscales, including "affective commitment", "normative commitment" and "continuance commitment". Thus the sub-hypotheses are verified that there is a significant and negative relationship between "affective commitment" and "turnover intentions" (SH1.1), between "continuance commitment" and "turnover intentions" (SH1.2) and between "normative commitment" and "turnover intentions" (SH1.3).

\section{Simple and multiple regression analysis predicting turnover intentions}

"In the presence of the three components of organisational commitment, turnover intentions minimize" (SH1.4). To test this hypothesis, simple and multiple regression analyses are 


\begin{tabular}{|c|c|c|c|c|c|}
\hline & Meyer & len's model for & $\mathrm{r}$ intentions su & & . Turnover \\
\hline & Subscale 1 & Subscale 2 & Subscale 3 & Subscale 4 & intentions for \\
\hline & $\begin{array}{l}\text { Affective } \\
\text { commitment }\end{array}$ & $\begin{array}{l}\text { Normative } \\
\text { commitment }\end{array}$ & $\begin{array}{l}\text { Continuance } \\
\text { commitment }\end{array}$ & $\begin{array}{l}\text { Turnover } \\
\text { intentions }\end{array}$ & IB employees \\
\hline $\begin{array}{l}\text { Subscale 1: Affective } \\
\text { commitment }\end{array}$ & - & & & & \\
\hline $\begin{array}{l}\text { Subscale 2: Normative } \\
\text { commitment }\end{array}$ & $0.768^{* *}$ & - & & & 149 \\
\hline $\begin{array}{l}\text { Subscale 3: Continuance } \\
\text { commitment }\end{array}$ & $0.504 * *$ & $0.492 * *$ & - & & \\
\hline $\begin{array}{l}\text { Subscale 4: Turnover } \\
\text { intentions }\end{array}$ & $-0.472^{* *}$ & $-0.615^{* *}$ & $-0.677^{* *}$ & - & Table \\
\hline $\begin{array}{l}\text { Note }(\mathbf{s}): * * \text { Correlation } \\
* \text { Correlation is significan }\end{array}$ & $\begin{array}{l}\text { icant at the } 0 \text {. } \\
0.05 \text { level }(2-t\end{array}$ & (2-tailed) & & & $\begin{array}{r}\text { Correlations between } \\
\text { the subscales }\end{array}$ \\
\hline
\end{tabular}

applied to predict the turnover intentions subscale (1) from each of the three organisational commitments subscales taken alone, (2) from the three probable pairs of the organisational commitments subscales and (3) from all three organisational commitments taken simultaneously. Table 2 summarises the results.

The outcomes show that when additional organisational commitment subscales are further inserted into the regression equations, the amount of outcome subscale variance explained certainly increases. Besides, the " $R$-square change" shows a significant $F$-change ( $p$-values smaller than $5 \%$ ) for all cases, implying that including the additional organisational commitment subscales to the regression significantly improves the prediction.

Knowing that an increase in the amount of subscale variance explained is noticed when predictors are added to the regression with a significant $F$-change and knowing that subscales of the three organisational commitment subscales are themselves significantly intercorrelated (median correlation $=0.266$ ), the hypothesis that turnover intentions are minimised when all organisational commitments are present (SH1.4) is verified. This means that an employee who experiences all the three organisational commitment levels is more able to show low turnover intentions.

Thus, indeed, turnover intentions are influenced by organisational commitment and the hypothesis $\mathrm{H} 1$ is validated

\section{Organisational efficiency and individual differences as moderators}

Group analyses are applied to check the extent to which the individual difference subscales of age, gender and social rank as well as organisational efficiency moderate the employees' reactions to their jobs, i.e. to examine the extent to which the individual differences and

\begin{tabular}{lc}
\hline & Average $R^{2}$ \\
\hline Number of predictors used in regressions & Turnover intentions \\
One $(\mathrm{AC} ; \mathrm{NC} ; \mathrm{CC}) *$ & 0.117 \\
Two $(\mathrm{AC}+\mathrm{NC} ; \mathrm{AC}+\mathrm{CC} ; \mathrm{NC}+\mathrm{CC})$ & 0.216 \\
Three $(\mathrm{AC}+\mathrm{NC}+\mathrm{CC})$ & 0.422 \\
Note $(\mathbf{s}): * n=324 . \mathrm{AC}=$ affective commitment; $\mathrm{NC}=$ normative commitment and $\mathrm{CC}=$ continuance \\
commitment
\end{tabular}

Table 2.

Average \% of variance explained in regressions predicting turnover intentions subscale from one, two and three organisational commitment subscales 
IJIF

14,2

150

organisational efficiency affect the strength of the relation between "organisational commitment" and "turnover intentions". Groups are created for each individual difference subscale. Comparisons are made between the correlations in the groups of each subscale at the following potential site: "organisational commitment" with "turnover intentions". Fisher's $Z$ is then applied to examine the importance of the variations between corresponding correlations in the groups of each individual difference subscale and organisational commitment.

The research framework notes that employee's individual differences [age, gender and social class ("upper", "middle" and "lower")] and organisational efficiency moderate employee's responses towards their jobs at two points in the relationships.

More specifically, it is expected that the link between "organisational commitment" and "turnover intentions" is stronger (1) for young employees than for aged ones, (2) for females than for males, (3) for employees who belong to the lower social class than those who belong to the upper social class and (4) for employees working in successful organisations than those who work in organisations facing difficulties.

That is, employees of different ages, different gender and different social classes are expected to experience the organisational commitment of a job in a significantly different way and are more likely to react differently to that experience. It is also expected that employees' commitment to successful organisations better predict their turnover intentions than employees' commitment to organisations with financial difficulties.

To test the moderation effects of these individual differences and organisational efficiency on the relationship between "organisational commitment" and "turnover intentions", the single scale which summarises the extent to which all three components of organisational commitment are simultaneously present is correlated with "turnover intentions" separately for each of the employee individual differences groups and for each group of organisations. Statistical significance of the differences between the correlations of each group and within each of the groups are statistically significant ( $p$-values were combined according to Fisher's product method (Fisher, 1925; Mosteller and Bush, 1954).

Table 3 illustrates the link between "organisational commitment" and "turnover intentions" for young (18-23-year-old) and older (over 40-year-old) employees, for male and female employees, for upper- and lower-class employees and for employees working in successful organisations and those working in organisations with financial difficulties. It also illustrates Fisher's Z-values in relation to the comparison of corresponding correlations. All differences are statistically significant and are in the predicted direction.

Consequently, the present outcomes provide strong statistical support for the role of age, gender, social class and organisational efficiency as moderators in the link between "organisational commitment" and "turnover intentions". When all comparisons are considered together, all of them are significant and corresponding correlations are in the expected direction.

Finally, knowing that research results verified the moderation role of individual differences and organisational efficiency in affecting the link between "organisational commitment" and "turnover intentions", hypothesis (H2) is verified.

\section{Discussion and analysis}

The present study provides a particularly rigid test of the links amongst Meyer and Allen's three organisational commitments, and their effect on reducing turnover intentions by using data obtained from employees of IBs during the lockdown. It is helpful, hence, to look at the outcomes of this research. Descriptive statistics were conducted. Results showed that all scales and subscales are normally distributed. In addition, some preferences for employees were detected: (1) high interest in jobs which meet their expectations in terms of pay and (2) high concern about their experienced psychological states and work motivation and satisfaction. The relationships 


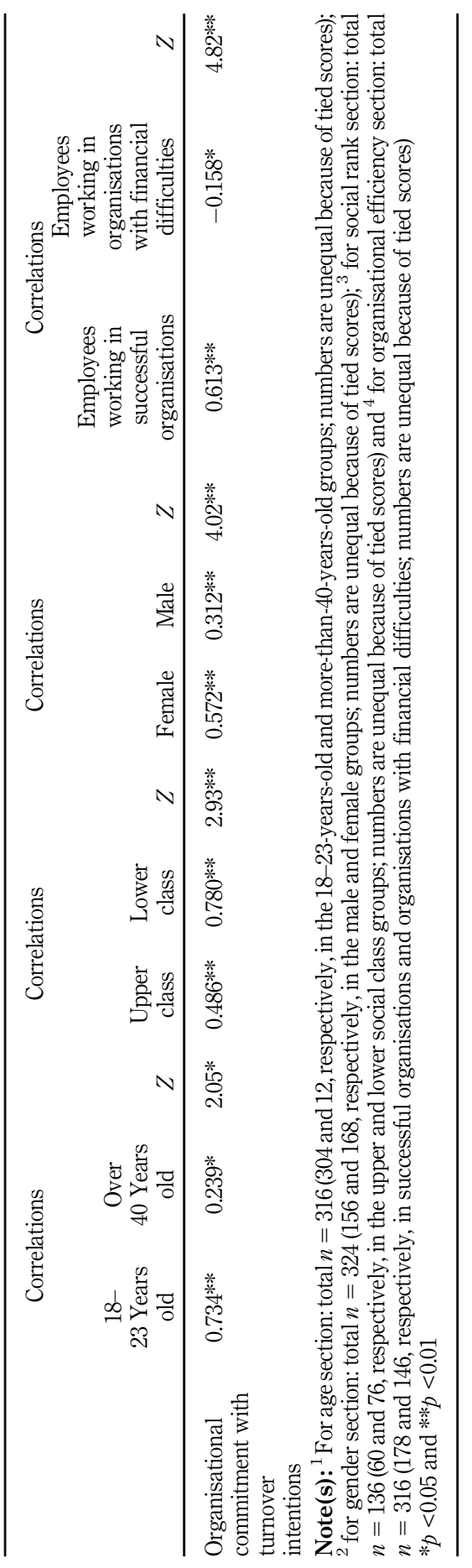

Table 3.

Testing the moderating effect of age, gender and social rank as well as organisational efficiency in the relationship between organisational commitment and turnover intentions 
IJIF

14,2

152

amongst the various subscales were tested. Zero-order correlations amongst the various subscales showed that affective, normative and continuance commitments are highly significantly correlated as well as "organisational commitment" and "turnover intentions". This result was previously found whilst testing the original model and was expected. Thus, the sub-hypotheses that there is a significant and negative relationship between affective commitment and turnover intentions (SH1.1), between continuance commitment and turnover intentions (SH1.2) and between normative commitment and turnover intentions (SH1.3) were verified. Through regression analysis, there was a strong support for the sub-hypothesis SH1.4 (in the presence of all organisational commitment subscales, turnover intentions were minimised.), and thus it was confirmed that turnover intentions minimise in the presence of all three organisational commitment subscales. By using zero-order correlation and Fisher's Ztest, it was confirmed that individual differences and organisational efficiency moderate the relationships between "organisational commitment" and "turnover intentions"; thus, hypothesis H2 (individual differences and organisational efficiency are moderators affecting the relationship between organisational commitment and turnover intentions) was verified. In particular, individual differences provide strong statistical support for the role of age, gender and social class as highly influential on the linkages between "organisational commitment" and "turnover intentions".

Overall, knowing the importance of employees' emotional states in guiding their future plans, effective employment retention strategies should aim to create and boost employees' positive emotional states as a key measure towards reducing their turnover intentions (Davidson et al., 2013; Serhan and Serhan, 2019; Serhan et al., 2021). However, knowing that the world is passing through its hardest-ever lockdowns where there are no new job offers and where turnover intentions are minimised, especially since other alternatives are almost nonexistent, employees' reactions to their job environment are being exceptional. Employees show a very low-turnover intention level though organisational commitment might be low especially for those working in banks with financial difficulties due to this lockdown. Although employers may not be able to improve remunerations and ensure job security in the current environment, they can undertake the following measures to create a feeling of organisational commitment and thus keep their best employees. Employers should offer jobs that are rich in the core job dimensions, strengthen the technical and communication skills of their employees, guarantee equal employment rights, apply labour laws and create favourable working environments.

In a previous theoretical research study, Jaros (2009) concluded that instruments that are considered as suitable measurements of organisational commitment lose their accuracy with time.

\section{Conclusion}

This research contributes to theory by enhancing the knowledge and providing an in-depth understanding of the relation linking "organisational commitment" to "turnover intentions" in IBs. It fills in the literature gap that highlighted a shortage of empirical work on the determinants of turnover intentions amongst IB employees and during the lockdown. This contribution deepens the knowledge about the employees' attitudes in a non-Western context.

Further, this research represents a significant addition to practice for as it provides employers and practitioners with reflective knowledge about employees' feelings and behaviour towards their jobs and the local labour market to which they belong. It enables them to be aware about the aspects that should be mainly considered so as to increase employees' stay at the company.

Finally, the generalisability of findings is still limited to the Islamic banking context in the UAE, Oman and Lebanon. Whilst the sample design was intended to enhance the strength of 
generalisability of results, it is crucial to expand this research to additional countries and other cultural backgrounds. Further, though the turnover intention can be regarded as a behavioural approach, it is fundamentally useful as a link between attitudes and behaviours (Romeo et al.,2020; Živković et al., 2021); nevertheless, it cannot be considered as behaviour by itself. Thus, it is significant to consider for future research additional behaviours associated with organisational commitment such as work performance and job pro-activity.

\section{References}

Akram, H. and Rahman, K.U. (2018), "Credit risk management: a comparative study of Islamic banks and conventional banks in Pakistan", ISRA International Journal of Islamic Finance, Vol. 10 No. 2, pp. 185-205, doi: 10.1108/IJIF-09-2017-0030.

Algabry, L., Alhabshi, S.M., Soualhi, Y. and Alaeddin, O. (2020), "Conceptual framework of internal Shariah audit effectiveness factors in Islamic banks", ISRA International Journal of Islamic Finance, Vol. 12 No. 2, pp. 171-193, doi: 10.1108/IJIF-09-2018-0097.

Al-Jabari, B. and Ghazzawi, I. (2019), "Organisational commitment: a review of the conceptual and empirical literature and a research agenda", International Leadership Journal, Vol. 11, pp. 78-119.

Ali, A.M. (2020), "The impact of economic blockade on the performance of Qatari Islamic and conventional banks: a period-and-group-wise comparison", ISRA International Journal of Islamic Finance, Vol. 12 No. 3, pp. 419-441, doi: 10.1108/JJIF-04-2020-0083.

Allen, N.J. and Meyer, J.P. (1984), "Testing the side-bet theory of organisational commitment: some methodological considerations", Journal of Applied Psychology, Vol. 69, pp. 372-378.

Allen, N.J. and Meyer, J.P. (1990), "The measurement and antecedents of affective, continuance and normative commitment", Journal of Occupational Psychology, Vol. 63, pp. 1-18.

Allen, N.J. and Meyer, J.P. (1993), "Organisational commitment: evidence of career stage effects", Journal of Business Research, Vol. 26, pp. 49-61.

Allen, N.J. and Meyer, J.P. (1996), "Affective, continuance and normative commitment to the organisation: an examination of construct validity", Journal of Vocational Behaviour, Vol. 49, pp. 252-276.

Babajide, E.O. (2010), "The influence of personal factors on workers' turnover intention in work organisations in south-west Nigeria", Journal of Diversity Management, Vol. 5 No. 4, pp. 1-10.

Benaicha, M. (2020), "An analysis of the normative parameters of reward and risk in Islamic finance", ISRA International Journal of Islamic Finance, Vol. 12 No. 3, pp. 303-323, doi: 10.1108/IJIF-072019-0100.

Bergjan, M. and Hertel, F. (2013), "Evaluating students' perception of their clinical placements: testing the clinical learning environment and supervision and nurse teacher scale (CLES+T scale) in Germany", Nurse Education Today, Vol. 33 No. 11, pp. 1393-1398.

Cohen, A. (2003), Multiple Commitments in the Workplace: an Integrative Approach, Lawrence Erlbaum Associates, New York.

Cronbach, L.J. (1971), “Test validation”, in Thorndike, R. (Ed.), Educational Measurement, 2nd ed., American Council on Education, Washington DC, p. 443.

Davidson, B.I., Desai, N.K. and Gerard, G.J. (2013), "The effect of continuous auditing on the relationship between internal audit sourcing and the external auditor's reliance on the internal audit function", Journal of Information Systems, Vol. 27, pp. 41-59, doi: 10.2308/isys-50430.

Delistavrou, A., Katrandjiev, H., Sadeh, H. and Tilikidou, I. (2019), "Exploring ethical consumption in different geographical places", EuroMed Journal of Business, Vol. 14 No. 3, pp. 221-238, doi: 10.1108/EMJB-10-2018-0059.

Dey, T. (2012), "Predictors of organisational commitment and union commitment: a conceptual study", IUP Journal of Organisational Behavior, Vol. 11, pp. 62-75. 
IJIF

14,2

Firestone, W.A. and Pennell, J.R. (1993), "Teacher commitment, working conditions and differential incentive policies", Review of Educational Research, Vol. 63 No. 4, pp. 489-525.

Fisher, R.A. (1925), Statistical Methods for Research Workers, Oliver and Boyd, Edinburgh.

George, D. and Mallery, M. (2010), SPSS for Windows Step by Step: A Simple Guide and Reference, 17.0 update (10a Edn.), Pearson, Boston.

Guzeller, C.O. and Celiker, N. (2020), "Examining the relationship between organisational commitment and turnover intention via a meta-analysis", International Journal of Culture, Tourism and Hospitality Research, Vol. 14 No. 1, pp. 102-120, doi: 10.1108/IJCTHR-05-2019-0094.

Hall, K. (1970), “An r-dimensional quadratic placement algorithm”, Management Science, Vol. 17 No. 3, pp. 219-229.

Hofstede, G. (2001), Culture's Consequences: Comparing Values, Behaviors, Institutions, and Organisations Across Nations, 2nd ed., Sage Publications, Thousand Oaks CA.

Hussain, A., Khan, M. and Hussain, J. (2020), "Interplay of organisational commitment and turnover intention in academic sector", Review of Economics and Development Studies, Vol. 6, pp. 501-512, doi: 10.47067/reads.v6i2.218.

Islam, R. and Ahmad, R. (2020), "Mudạrabah and mushärakah as micro-equity finance: perception of Selangor's disadvantaged women entrepreneurs”, ISRA International Journal of Islamic Finance, Vol. 12 No. 2, pp. 217-237, doi: 10.1108/JJIF-04-2018-0041.

Jaros, S. (2009), "Measurement of commitment", in Klein, H.J., Becker, T.E. and Meyer, J.P. (Eds), Commitment in Organisations: Accumulated Wisdom and New Directions, Routledge Academic, Ohio, pp. 347-382.

Jehanzeb, K., Rasheed, A. and Rasheed, F. (2013), "Organisational commitment and turnover intentions: impact of employee's training in private sector of Saudi Arabia”, International Journal of Business and Management, Vol. 8, pp. 79-90, doi: 10.5539/ijbm.v8n8p79.

Kim, K. and Jogaratnam, G. (2010), "Effects of individual and organisational factors on job satisfaction and intent to stay in the hotel and restaurant industry", Journal of Human Resources in Hospitality and Tourism, Vol. 9, pp. 318-339, doi: 10.1080/15332845.2010.487043.

Kraska, R.A., Weigant, M. and Geraedts, M. (2017), "Associations between hospital characteristics and patient satisfaction in Germany”, Health Expect, Vol. 20 No. 4, pp. 593-600, doi: 10.1111/hex.12485.

Kumari, N. (2017), "A comparative study of performance management system in IT/ITES industry", London Journal Press, Vol. 17 No. 1, pp. 1-10.

Long, C.S. and Thean, L.Y. (2011), "Relationship between leadership style, job satisfaction and employees' turnover intention: a literature review”, Research Journal of Business Management, Vol. 5, pp. 91-100, doi: 10.3923/rjbm.2011.91.100.

Maertz, C.P. and Boyar, S.L. (2012), "Theory-driven development of a comprehensive turnoverattachment motive survey", Human Resource Management, Vol. 51, pp. 71-98.

Mallat, A., Vrontis, D., Thrassou, A. and Nemer, S. (2020), "Patient satisfaction in the context of publicprivate partnerships", International Journal of Organisational Analysis, Vol. 29 No. 6, pp. 13951422, doi: 10.1108/IJOA-03-2020-2066.

Meyer, J.P. and Allen, N.J. (1991), "A three component conceptualization of organisational commitment", Human Resource Management Review, Vol. 1, pp. 61-89.

Meyer, J.P. and Allen, N.J. (1997), Commitment in the Workplace: Theory, Research, and Application, Sage Publications, Thousand Oaks, CA.

Meyer, J.P., Allen, N.J. and Smith, C.A. (1993), "Commitment to organisations and occupations: extension and test of a three-component conceptualization", Journal of Applied Psychology, Vol. 78 No. 4, pp. 538-551, doi: 10.1037/0021-9010.78.4.538.

Meyer, J.P., Stanley, D.J., Herscovitch, L. and Topolynsky, L. (2002), "Affective, continuance, and normative commitment to the organisation: a meta-analysis of antecedents, correlates, and consequences", Journal of Vocational Behavior, Vol. 61 No. 1, pp. 20-52. 
Meyer, J.P., Morin, A. and Wasti, S.A. (2018), "Employee commitment before and after economic crisis: a stringent test of profile similarity", Human Relations, Vol. 71 No. 9, pp. 1204-1233.

Morrow, P.C. (1983), "Concept redundancy in organisational research: the case of work commitment", Academy of Management Review, Vol. 8 No. 3, pp. 486-500.

Mosteller, F. and Bush, R.L. (1954), "Selected quantitative techniques", in Lindzey, G. (Ed.), Handbook of Social Psychology, Addison-Wesley, Reading, MA, Vol. 1.

Moussa, M.N. (2013), "Effects of perceived procedural justice and exchange ideology on employees' affective commitment: evidence from Saudi Arabia”, International Journal of Business and Management, Vol. 8, pp. 81-89, doi: 10.5539/ijbm.v8n15p81.

Mowday, R.T., Steers, R.M. and Porter, L.W. (1979), "The measurement of organisational commitment", Journal of Vocational Behaviour, Vol. 14, pp. 224-247.

Papastavrou, E., Karlou, C., Tsangari, H., Efstathiou, G., Sousa, V., Merkouris, A. and Patiraki, E. (2016), "Cross-cultural validation and psychometric properties of the Greek version of the caring behaviors inventory: a methodological study", Journal of Evaluation in Clinical Practice, Vol. 17, pp. 435-443.

Pitts, D., Marvel, J. and Fernandez, S. (2011), "So hard to say good-bye? Turnover intention among US federal employees”, Public Administration Review, Vol. 71 No. 5, pp. 751-760, doi: 10.1111/j.15406210.2011.02414.x.

Porter, E. (1974), "The contributions of industrial organisation to strategic management", The Academy of Management Review, Vol. 6 No. 4, pp. 609-620.

Rafikov, I. and Akhmetova, E. (2020), "Methodology of integrated knowledge in Islamic economics and finance: collective ijtihad", ISRA International Journal of Islamic Finance, Vol. 12 No. 1, pp. 115-129, doi: 10.1108/IJIF-02-2019-0034.

Rawashdeh, A. and Tamimi, S. (2019), "The impact of employee perceptions of training on organisational commitment and turnover intention: an empirical study of nurses in Jordanian hospitals", European Journal of Training and Development. doi: 10.1108/EJTD-07-2019-0112.

Redditt, J., Gregory, A.M. and Ro, H. (2019), "An examination of organisational commitment and intention to stay in the timeshare industry: variations across generations in the workplace", International Journal of Hospitality and Tourism Administration, Vol. 20 No. 2, pp. 206-225, doi: 10.1080/15256480.2017.1359735.

Romeo, M., Yepes-Baldó, M. and Lins, C. (2020), "Job satisfaction and turnover intention among people with disabilities working in special employment centers: the moderation effect of organisational commitment", Frontiers in Psychology, Vol. 11 No. 1035, doi: 10.3389/fpsyg.2020.01035.

Serhan, M. and Serhan, C. (2019), "The impact of food service attributes on customer satisfaction in a rural university campus environment”, International Journal of Food Science, Vol. 1, pp. 1-12, doi: $10.1155 / 2019 / 2154548$.

Serhan, C. and Tsangari, H. (2019), "Reliability and validity of a modified job diagnostic survey for fresh graduates' retention", Academy of Strategic Management Journal, Vol. 18 No. 5, pp. 1-17.

Serhan, C., Tsangari, H., Sanchez Bengoa, D. and Mekdessi, S. (2016), "Fresh graduates' retention: a review of literature", IOSR Journal of Business and Management, Vol. 18 No. 2, pp. 51-64.

Serhan, C., Salloum, W. and Abdo, N. (2021), "How reward systems affect team performance in banks: evidence from the Middle East and North Africa (MENA) region", Team Performance Management, Vol. 27 Nos 5/6, pp. 446-465, doi: 10.1108/TPM-03-2021-0022.

Shang, R., Abernethy, M.A. and Hung, C. (2019), "Group identity, performance transparency, and employee performance", The Accounting Review. doi: 10.2308/accr-52652.

Sheldon, M.E. (1971), "Investments and involvements as mechanisms producing commitment to the organisation", Administrative Science Quarterly, Vol. 16, pp. 143-150.

Shierholz, S., Nabadish, N. and Wething, H. (2012), Labor Market for Young Graduates Remains Grim, Briefing Paper \# 340, Economic Policy Institute, Washington DC.

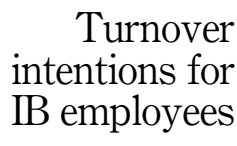

155 
IJIF

14,2

Tahirijouti, A. (2018), "Islamic finance: financial inclusion or migration?", ISRA International Journal of Islamic Finance, Vol. 10 No. 2, pp. 277-288, doi: 10.1108/IJIF-07-2018-0074.

Thrassou, A., Santoro, S., Leonidou, E., Vrontis, D. and Christofi, M. (2020), "Emotional intelligence and perceived negative emotions in intercultural service encounters: building and utilizing knowledge in the banking sector", European Business Review, Vol. 32 No. 3, doi: 10.1108/EBR04-2019-0059.

Tsangari, H. (2017), Decision Making Methods and Tools, Lecture Notes, University of Nicosia, Nicosia, Cyprus.

Vizcaya-Moreno, M.F., Pérez-Ca-averas, R.M., De Juan, J. and Saarikoski, M. (2015), "Development and psychometric testing of the clinical learning environment, supervision and nurse teacher evaluation scale (CLES+T): the Spanish version”, International Journal of Nursing Studies, Vol. 52 No. 1, pp. 361-367, doi: 10.1016/j.jnurstu.2014.08.008.

Vrontis, D., Sakka, G. and Amirkhanpour, M. (2015), Management Innovation, Entrepreneurship and Human Resource Management Practices: A Global Perspective, Cambridge Scholars.

Živković, A., Franjković, J. and Dujak, D. (2021), "The role of organisational commitment in employee turnover in logistics activities of food supply chain”, LogForum, Vol. 17 No. 1, pp. 25-36, doi: 10.17270/J.LOG.2021.536.

\section{About the authors}

Carole Serhan, $\mathrm{PhD}$, is Assistant Professor of Business Management and Administration at the Issam Fares Faculty of Technology, University of Balamand, Lebanon. The focus of her publications is on employment motivation and job satisfaction. Carole Serhan is the corresponding author and can be contacted at: carole.serhan@balamand.edu.lb

Nehmeh Nehmeh is a regional consultant for various Islamic banks in the UAE and Oman. He holds an MBA degree from the University of Balamand.

Ibrahim Sioufi is auditor at many banks in Lebanon and has a number of years of experience within the commercial banking system. He holds an MBA degree from the University of Balamand.

For instructions on how to order reprints of this article, please visit our website:

www.emeraldgrouppublishing.com/licensing/reprints.htm

Or contact us for further details: permissions@emeraldinsight.com 